\title{
Symbolism in Edgar Allan Poe's Selected Short Stories
}

\author{
Hatameh Sadat Jandaghi \\ Vali-e-Asr University, Iran \\ Esmaeil Zohdi \\ Department of English, Vali-e-Asr University of Rafsanjan, Iran
}

\begin{abstract}
In Edgar Allan Poe's short stories symbolism is the main figure of speech of his stories. The main aim of this study is recognizing the use of symbolism in "Hop - Frog" (1850), "The Pit and the Pendulum" (1842) and "The Cask of Amontillado" (1846), and decoding the symbols and various meanings they signify according to Herman Northrop Frye's theory. This paper tries to explore the way symbolism is used in Edgar Allan Poe's selected short stories, the writer's motives and amount of his success.
\end{abstract}

Index Terms - symbolism, symbol, stylistic devices, herman northrop frye, Hop - Frog, The Pit and the Pendulum, The Cask Of Amontillado

\section{INTRODUCTION}

Figures of speech are tools of creativity in everyday communications and the literature that is used to explain something different from ordinary usage. "The Collins English Dictionary (2006) defined figure of speech as 'an expression such as simile, in which words do not have their literal meaning, but are categorized as multi - word expressions that act in the text as units" (As cited in Fadaee, 2011, p. 1). A language which uses figures of speech is called "figurative language" and according to Ghaffar Tajalli's "Idioms and Metaphorical Expressions in Translation" (2003) the aim of figurative language is to supply features of clarity, beauty and others in the language. It should be mentioned that figurative meaning brings vagueness that influences the simplicity or clarity of language. Metaphor, simile and the like are specific elements of figurative language that differentiate it from nonfigurative language.

Stylistic devices play an important role in literary works, especially in obtaining different meanings; but symbolism has a different value because it makes the story more rich in meaning for readers and help them relate themselves to the characters and plot. Symbolism is among stylistic devices, which has been used a lot in previous literary works, as the works of Chaucer and Shakespeare. Symbols are used to add beauty to work and decorate a work of art and in some cases for purposes such as political, social and cultural.

According to Oxford Advanced Learner's Dictionary of Current English (2005), symbolism is "The use of symbols to represent ideas, especially in art and literature" (p. 1556). Symbolism have always been present in human history and mankind seems to have been inclined transferring novel ideas and their thoughts through symbols and signs and depict their world in an abstract way. For example, ancient Egypt inhabitants consider the Ankh as a symbol of life and the Uraeus, a Cobra with a bright hood, the symbol of protection of underworld's doorways. Among literary devices which writers use to create other level of meaning, symbolism play a crucial role. As Djaafour Fouzia (2014) states "symbolism in literature evokes interest in readers as they find an opportunity to get an insight of the writer's mind on how he views the world and how they think of common objects and actions, having broader implications" (p. 5). According to Nora Cherrat (2012), Karen Bernado interpreted symbolism as "An integral component of fiction because it enriches the narrative by pulling its message down to the level of our unconscious and anchoring there" (p. 15). Symbolism, as a school refers to three stages of an important part of the literary modernism's development: 1) to an artistic progress during the last decades and a half of the $19^{\text {th }}$ century in France and Belgium, 2) to its actual sources in French poetry that began in the 1850s, and 3) and how the American and European literature was affected by the above stages in the $20^{\text {th }}$ century. Symbolism came to existence in last years of the $19^{\text {th }}$ century and it founded by Charles Baudelaire (1827- 67). Paul Verlaine (1844 - 96), Arthur Rimbaud (1854 - 91) and Stephan Mallarme (1842 - 98) are among the most famous figures in symbolism whose works were greatly influenced by Baudelaire and proceeded to creat their own innovative styles which later served as primary sources of influences on other writers outside France.

Symbolism is so intertwined with modern arts which is an important part of a literary work. Maurice Maeterlinck, Richard Aldington, and Aldous Huxley are famous figures of this school. For example "A Portrait of the Artist as a Young Man" by James Joyce, "La Princesse Maleine" (Princess Maleine) by Maurice Maeterlinck, "Le Spleen de Paris" (Parisian Dream) and "Le Voyage" (The Voyage) by Charles Baudelaire are among the most famous symbolic literature. In symbolic painting Paul Gauguin paintings are noticeable. According to Harschel B. Chipp (1984), Gauguin describes his self- portrait which ordered by Vincent as "I believe it is one of my best things: absolutely incomprehensible it is so abstract" (p. 67). As Emerging Infectious Diseases journal (2003) mentions Pablo Picasso as 
one of the painters who used symbols in his works, believes “... The public who look at the picture must interpret the symbols as they understand them" (p. 760). In symbolic poems, symbols are emotional and mixed with music and picture; and poets aggraded the way for symbolic music by their symbolic poems. According to the early studies of famous German musicologist, who were interested in mime harmonic techniques, Claude Debussy, a French composer, is considered a famous symbolist.

J. E. Cirlot (1971) in the introduction of his dictionary A Dictionary of Symbols states that according to Paul Diel "the symbol is a vehicle at once universal and particular. Universal, since it transcends history; particular, because it relates to a definite period of history" (p. xvi).

Edgar Allan Poe, an American poet, author, literary critic and editor, was born January 19,1809 in Boston and died October 7, 1849 in Baltimore. When Edgar was one, his father died and his mother died next year. And John Allan adapted Edgar after his mother death. Allan Poe is considered as one of the greatest American writers. He is best known for his mysterious tales and he is considered the inventor of a new genre, detection genre. Poe was alcoholic and this matter affects his writing. As his father and brother were alcoholic, maybe it was a genetic inclination to it. His mysterious and suspense stories are still read in the entire world. Poe's poems and tales' characters are distressed by unknown fears. Most of Poe's works are rich of symbols, because symbolism is the final tool for him to write and mention a lot of things without speaking directly. Studying Poe's biography shows that his tales and poems mirror the author's life.

To understand the relation between Poe's tales and his life one must know that, despite his enemies' belief, Poe was not a steady drinker. As Trent McDonald says in Seeing Poe's Fight with Alcoholism through his Stories "The Black Cat" and "The Cask of Amontillado", "The truth is there were long periods when he was sober, often years, followed by short periods of terrible binges. During these binges ... poe would lose control and occasionally become fall-down drunk" (p. 12). He knew himself as an alcoholic person and tried to control his tendency. On November 1846, when he was in one of his abstemious period, he wrote "The Cask of Amontillado" in which the tone shows his condition. Poe was serious in his sobriety; so he attended the Sons of Temperance in Richmond VA. Although when Poe was writing "The Black Cat" he couldn't reduce his alcoholic tendencies, but in "The Cask of Amontillado" time it seems he found a way. When looking carefully at Poe's tales and the difference between them, his various periods in life, which are related to his addiction, become identifiable. As Poe belongs to the romantic period, talking about the basic of this era is necessary. This period, named Romantic period, was from 1828 to 1865 in America. American literary Romanticism started with English Romantic poets, especially Coleridge and Wordsworth, and also with the German Romantic philosophy.

The scope of this study is to identify and explore the function of symbolism in Poe's selected short stories. Frye's vision on symbolism will be discussed within the study in the following short stories by Edgar Allan Poe: "Hop - Frog" (1850), "The Cask of Amontillado" (1846), and "The Pit and The Pendulum" (1842).

\section{DISCUSSION}

Symbolism is very useful in defining literature and arts. There are two types of symbols, conventional and personal, that are use in interpreting arts, literature, dreams and experiences; conventional and personal.

\section{Conventional Symbols (cultural or universal):}

Cultural background is a key element in understanding signs. In other words, meanings of signs for people who have the same cultures are identical. Meanings of signs are different from one culture to another culture, and sometimes a sign has a completely different meaning in another cultural context. Most of the time,For example, the wedding dress color in Iran is white, but in India white dress is worn in funerals. Notice that symbols are man-made.

\section{Personal Symbols (contextual or private):}

Personal symbols change from one person to another person; author, dreamer, artist, etc. for example, when two persons hear the word "Heart", their interpretation of this word may be different; one considers it just as an organ of the body while the other consider it as the center of emotions, especially love.

Many theorists and scholars such as Ferdinand De Saussure, Alfred North Whitehead, Susanne Langer, Northrop Frye and others seem to be prominent figures in providing and constructing theories of symbolism; however, in this paper the Frye's vision is taken into account.

\section{A. Frye's Theory of Symbolism}

Herman Northrop Frye (1912 - 1991) is a Canadian literary critic and literary theorist who is known as one of the most authoritative theoretician of the $20^{\text {th }}$ century. Frye's first book, fearful symmetry (1947), brought him a worldwide fame that led him to a new interpretation of William Blake's poetry. Frye's most significant works of literary theory, Anatomy of criticism (1957), is one of the greatest works of the $20^{\text {th }}$ century.

Theory of symbols by Frye is combined with the analysis of criticism. Literature can be understood by contextual reading where phases are considered as contexts. Generally, the aim of phases is describing critical moves rather than literary forms so they present manner and process of analyzing symbols. Symbols are used to give meaning to every unit of literary construction that can be apart and different from critical attention. This vast definition caused Frye to link each phase with relevant or proper kind of symbolism, and by doing so, he defined the phase at the best level of 
generality. Frye's theory of symbol has five phases. Literal Phase: Symbol as Motif, Descriptive Phase: Symbol as Sign, Formal Phase: Symbol as Image, Mythical Phase: Symbol as Archetype, and Anagogic Phase: Symbol as Monad. There are two more additional classes which are the basis of Frye's definition of the phases: Narrative (Mythos) and meaning (Dianoia). The narrative relates to rhythm, movement, repetition, and act; and meaning relates to motif, structure, parity, and dream. Frye in his "Anatomy of Criticism" insists on two directions that a reader's attention moves to; Outward or Centrifugal and Inward or Centripetal. The outward direction is the one in which the reader goes outside of reading, the second one, inward, is the one where the reader tries to find the meaning from the word in the text.

\section{B. Symbolism in "Hop - Frog"}

Hop - Frog, written in 1850, which is about two dwarfs who are led into captivity to become dwarfs of the king. The king and his council insult them and make them tools for joking and laughing. One day Hop - Frog makes a decision to revenge. For a party, Hop-Frog dresses the king and seven ministers as orangutans and by a deliberate plan sets them fire. Hop - Frog and his partner, Trippetta, escape to another land and nobody sees them forever.

King, as an outward symbol, is the symbol of a tyrant who knows all the people as his slaves and is allowed to despise them because he is their owner or king. As for inward symbol, it should be mentioned that when Poe's father and mother die, his rich foster father John Allan, adopts him. King is the symbol of Poe's foster father. As king abused Trippetta and Poe's foster father did the same toward his wife. And the king is also symbol of his actual father.

Hop - Frog is a dwarf in a king's court. According to Juan Eduardo Cirlot (1971) "dwarf is symbol of ambivalent meaning. Like dactyls, elves and gnomes, the dwarf is the personification of those forces which remain virtually outside the orbit of consciousness. In folklore and mythology, the dwarf appears as a mischievous being, with certain childish characteristics befitting its small size, but also as a protector like the Cabiri - this being the case with the "woodland dwarfs' in the tale of Sleeping Beauty" (p. 91). But in terms of inward symbol, it is the symbol of Poe himself. Both Poe and Hop - Frog are taken away from their home and sent to live with the wealthy and cruel persons that rule over them; his foster father and king.

Trippetta was Hop - Frog's couple, caused him to revenge and helped him to do it. So, she can be the symbol of a big influence; the influence on taking vengeance or the influence on taking a successful vengeance. But according to the story and its background, it should be mentioned that two women, his foster mother and Trippetta, in Poe's life and Hop - Frog's life had important roles. Trippetta, as a symbol in Poe's life, symbolizes Poe's foster mother.

The orangutans are a species of extant great ape. Michael Ferber (2007) states "The Greeks and the Romans considered apes ridiculous, strange, ugly, and somewhat dangerous, and "ape" was a common term of abuse" (p. 12). But here Poe's intention was that these newly discovered creatures were extremely unintelligent, so they are very appropriate symbol of the king and his council member that Hop - Frog finds them stupid and credulous.

The parrot, at the window was a symbol for Hop - Frog and Tripetta. This parrot symbolizes their escape and survival from the king's palace which eventually happened by playing a trick on the tyrants. In fact, the parrot delivered this message to Hop - Frog by its presence. As for outward, parrot's meaning is a bit different; "Maurice Bouisson, in Le Secret de Schéhérazadé, comments on the Tuti nameh, a Persian translation of Nakchabi's Book of the Parrot. He comes to the conclusion that it is a messenger-symbol, like the crow, and also a symbol of the soul (the Egyptian $b a$ ), like other birds. In The Conference of the Birds, by the $13^{\text {th }}$-century Persian poet Farid Ud-Din Attar, the parrot seeks the water of immortality" (Cirlot, 1971, p. 250).

In general, Chains are symbols of punishment and something that Hop - Frog can take vengeance on the king and his seven ministers. In the "Hop - Frog", the chains symbolize Hop - Frog and Trippetta's enslavement by the king. Also, these chains are symbol of hard disciplines which the king rules his kingdom through them.

\section{Symbolism in "The Pit and the Pendulum"}

This short story is about a man who is sentenced to death, so he faints. When he wakes up, he finds himself in a dungeon. however, because of lack of sleep he faints again. He wakes up once more and finds that a swinging blade or pendulum comes closer and closer. Then he makes a plan to escape, in which he puts a piece of meat on the knots and ropes that hold him. Rats eat the knots and then he is released, but suddenly he sees walls that their shapes change into other different shapes. He struggles no more and prepares himself for death. however, General Lasalle, leader of the victorious French Army saves him in the last few moments.

The first symbols which are visible in its title are the pit and the pendulum. Pit is a kind of dungeon that can be the symbol of the narrator's dark fate waiting for him. The punishment's cost was the narrator's death by a pit, pendulum, rats and walls. So the pit also is the symbol of a place which life and death is in its hands. Its inward meaning is not far from its outward; the huge pit that the narrator nearly falls into is so mysterious, terrifying and like a hell for him- a hell which he will fall into after his death. Here the pit is symbol of hell waiting for the narrator. As for pendulum, pendulum's inward and outward meanings are related to each other, but are not the same or close. The Pendulum is a kind of timekeeping device that shows time. It is the symbol of time passing that says each condition is temporary in which something new is on the way and every moment is valuable. According to the following part of the story, the pendulum not only is the symbol of time but also death. Time and death have direct relation; pendulum's movement is the symbol of passing time and it means death is drawing near. "It might have been half an hour, perhaps even an hour, 
(for I could take but imperfect note of time) before I again cast my eyes upward. What I then saw confounded and amazed me. The sweep of the pendulum had increased in extent by nearly a yard" (Poe,1899, p. 209).

Rat's definition as outward symbol is "the rat occurs in association with infirmity and death. It was an evildoing deity of the plague in Egypt and China. The mouse, in mediaeval symbolism, is associated with the devil. A phallic implication has been superimposed upon it, but only in so far as it is dangerous or repugnant" (Cirlot, 1971, p. 271). But in inward description rats are the symbol of the savior. They helped the narrator to escape from the pendulum. As he says about them, "they were wild, bold, ravenous; their red eyes glaring upon me as if they waited, but motionlessness on my part to make me their prey" (Poe, 1899, p. 212), it is clear the narrator hates them at first, but when these disgusting creatures become his way of freedom, they became redeemer for him.

"Color symbolism is one of the most universal of all types of symbolism, and has been consciously used in the liturgy, in heraldry, alchemy, art and literature" (Cirlot, 1899, p. 52). We have two colors- black and red. There are several terms for "black" with subtle differences among them in Greek and Latin, but their symbolic meanings are similar and most of the time negative- as "bad" and "evil". For example "Dante's inferno is dark, with 'black air' as well as black devils and black angels and cherubim" (Ferber, 2007, p. 27). Although black is the color of death and mourning, in Christianity black is also sign of purity or modesty. Here black robes of judges are the reflection of their nature and soul, which is evil and sly. They look for the death of the narrator and enjoy it. "Red in literature is the color of fire, gold, and roses; it is the color of faces when they show embarrassment, anger, or the flush of health or passion. It is also the color of blood ..." (Cirlot, 1971, p. 169). For example, Mars is the symbol of God of bloody war because of its color which is red. In Renaissance poetry, red and white are often colors of love and beauty. "Red is sometimes the color of the devil ..." (Cirlot, 1971, p. 169). "Red symbolizes protection as John Buchanan-Brown stated in its book Dictionary of Symbols, 'Red dye ... with which women and girls in Black Africa paint their faces and bodies after the taboo following their first menstruction has been lifted, on the eve of their first marriage, or after the birth of their first child"” (Cherrat, 2012, pp. 60-61). In "The Pit and the Pendulum" Red is the symbol of devil's anger who is presented here by red walls. Their exasperation comes down on narrator and will cause his death. Red walls are coming toward him and become flatter. He can see death by his own eyes. In other words, here red is the symbol of anger, devil, blood and death in order.

\section{Symbolism in "The Cask of Amontillado"}

This story has two main characters, Montresor and Fortunato. Montresor feels revenge is the only way of compensating Fortunato's wrong. He meets Fortunato who was wearing jester costume at the carnival. Montresor manipulates him to go, tastes Amontillado and assures it is not Sherry. They go to catacomb, where the cask of Amontillado is. Fortunato has allergy and coughs continually. Montresor tries to dissuade him from going and tasting the wine but Fortunato wants to taste Amontillado. They go to the crypt and Montresor imprisons him with a chain. At first Fortunato thinks that it is just a joke, but Montresor leaves him there and builds a wall. As the narrator says the catacombs remain intact.

Amontillado is a kind of wine. Wine, especially red one, is the symbol of blood and sacrifice; and sometimes it signifies eternal life and youth. In this story Amontillado caused a successful revenge and Fortunato was the person who was being sacrificed. But primarily Amontillado tempted him to go toward death and temptation is the important factor in this case. So, Amontillado is the symbol of temptation here not sacrifice.

"In symbolism, numbers are not merely the expressions of quantities, but idea-forces, each with a particular character of its own. The actual digits are, as it were, only the outer garments. All numbers are derived from the number one ..." (Cirlot, 1971, p. 230). Two is the symbol of encounter, completion and the same time opposition- like life and death, immortal and mortal, good and evil, moon and sun. In "The Cask of Amontillado" two is the symbol of reflection, conflict and opposition. As Montresor says at the beginning of the story, "the thousand injuries of Fortunato I had ... I vowed revenge" (Poe, 1899, p. 258), he is Fortunato's enemy and just finds comfort by vengeance. Two expresses this feeling of revenge and hatred toward the enemy very well throgh reflection meaning which is the reflection of Fortunato's treacheries to Montresor. And as for number eleven which is generally "Symbolic of transition, excess and peril and of conflict and martyrdom. According to Schneider, there is an infernal character about it: since it is in excess of the number of perfection - ten - it therefore stands for incontinence; but at the same time it corresponds, like two, to the mandorla - shaped mountain, to the focal point of symbolic Inversion and antithesis, because it is made up of one plus one (comparable in a way with two)" (Cirlot, 1971, p. 234); while As the last row of bricks was the eleventh row, it was a real danger for Fortunato because he will die there. Eleven was also the symbol of a conflict which ended by his death and it showes that avenger Montresor goes beyond the bounds for revenge.

\section{CONCLUSION}

On the whole, it should be mentioned that despite Edgar Allan Poe's short life, he was brilliant in all his writings. His style was effective but simple in which the interpretation is difficult but understandable.

Most of the symbols used in Poe's selected works seem to be connected to the theme of death. He knew death as an important part of life, and always thought about it. Allan Poe lost all of his family during his lifetime. The death of his beloved wife offended him, so her loss pushed him to alcohol to escape from or forget this pain. 
At the beginning of the $20^{\text {th }}$ century the world was affected by two world wars. Humanity had no place among people. They forgot to be romantic or dutiful toward others. People changed into self-centered persons whose communication was in a low level with society. In the meantime, the "absurdist' movement appeared. The topics of their writings were like horror, suffering of life, death as an important part of life, lack of love, separation from their love and others which become Allan Poe's writing style. Poe was known as the society's mirror, mirror of their psyche. Maybe the reason of his gothic style was that he wanted to show gothic events of life as common events because society liked it; negative not positive. So, to do this task better, he decided to use symbols in his writing in order to tell number of things while his writing style is a short writing.

The main aim of this study was recognizing the use of inward symbolism interpretation as well as the outward one in the selected works, writer's motivation, and amount of his succeeding. Another aim of this work is to introduce symbolism as a common and beautiful figure of speech to EFL learners through Frye's symbolism theory on Edgar Allan Poe's selected short stories with theme of gothic and in some ways the same themes.

In the short story "The Cask of Amontillado", by the aid of symbols, Poe writes the story of two apparently friends but infact real enemies - called Fortunato and Montresor. Montresor's aim has been just a recompense and "two" and "eleven" which are the symbols of two friends and rows of wall as two important symbols which showed the process and end of this revenge very well. "The Cask of Amontillado" is a story which starts with symbolism from its title. "Amontillado" as the symbol of temptation from the beginning showing the end. And after a while, when the reader reads the story, grasps the point where Fortunato's life will finish here in this cellar because of temptation. There are some elements which make the environment of the story gothic and increase its influence such as the presence of some things like long and winding staircase, white web, pile of bones and black color. Each of the symbols has an important effect in making it more terrifying and exciting.

Likewise, "Hop Frog" is a story that symbolizes Poe's life and its characters. King, Hop frog, and Tripetta who are the main characters of the story are as foster father, Poe himself, and his foster mother in Poe's real life. He wrote this story with the use of symbols to show his life in a symbolic way. "Hop Frog" considers Poe's autobiography as results showes it. This fact is not stated anywhere in the story and the reader just finds it when reads Poe's biography and relates these two to each other. The procedure of this story is structured on the basis of symbolism which will be decoded by the reader. "Hop Frog" has other symbols like orangutans, a parrot and chains which show the condition of Hop Frog and Poe's life.

In the "The Pit and the Pendulum" the symbols, pit and the pendulum, are the most important features. They show a particular meaning in the story. They are elements which symbolize the fate awaiting the narrator. Symbolism suggestes many interpretations by the readers. Using first point of view in the story by Poe is a strategy to direct the reader's interpretation into the writer's purpose. This purpose is that the writer uses first point of view to show the story as real as possible and the reader lives those moments of fear with the narrator. This feature - using "I" narrator - influences the reader, makes the reader close to the writer and causes the reader to sympathize with him.

This study interpreted symbols according to Frye's symbolism theory in both directions -inward and outward. All of the selected words are symbols, just they have different meanings in some cases; like rats in The Pit and the Pendulum, "Amontillado" in The Cask of Amontillado, chains in Hop - Frog etc. In present work symbols in Hop - Frog are signs because Poe imitated this story from real events and described them with symbols, but in The Cask of Amontillado and The Pit and the Pendulum symbols are motif because they are symbolism, rhythm and movement of words, not realism or something else.

As mentioned before, symbols are conventional or personal. Most of the inward symbols in Hop - Frog are personal because the writer made and chose them himself according to his life. But other inward symbols in this story - Hop Frog -, The Pit and the Pendulum and The Cask of Amontillado are conventional because they completely depend on the story and its procedure and readers can interpret them by reading the story.

Edgar Allan Poe, as an agent of $20^{\text {th }}$ century people, could do his duty as an absurdist very well in using this figure of speech - symbolism - to write stories with themes of death, horror, suffering etc. In these stories he could show common themes of those days very effectively, in The Cask of Amontillado, he could express self-centering and fearing. In Hop - Frog, he also demonstreted his life which was a stressful, sad and lonely life. And in The Pit and The Pendulum, horror and fear of the narrator were shown through the use of symbols and symbolism.

\section{REFERENCES}

[1] Cherrat, N. (2012). The Function of Symbolism in Chinua Achebe's Novel Things Fall Apart. pp. 15, 60-61. Retrived from http://dspace.univ-biskra.dz:8080/jspui/bitstream/123456789/4495/1/dissertation.PDF.

[2] Chipp, H. B., Selz, p. \& Taylor, J. C. (1984). Theories of Modern Art: A Source Book by Artists and Critics. Symbolism and other Subjectivist Tendencies: form and the Evocation of Feeling (revised ed., PP. 48 - 57). University of California Press, Berkeley.

[3] Cirlot, J. E. (1971). A Dictionary of Symbols ( $2^{\text {nd }}$ ed., J. Sage, Trans.). Routledge, London.

[4] Davies, W. V. (1987). Reading the Past: Egyptian Hieroglyphs. University of California Press, Oakland.

[5] Fadaee, E. (February 2011). Symbol, metaphors and similes in literature: A case study of 'Animal Farm'. Journal of English and Literature (vol. 2), p. 1. Retrived November, 2016, from http://academicjournals.org/journal/IJEL/article-full-textpdf/39296CD965. 
[6] Ferber, M. (2007). A Dictionary of Literary Symbols (2 ${ }^{\text {nd }}$ ed.). Cambridge University Press, Cambridge .

[7] Frye, H. N. (2000). Anatomy of Criticism Four Essays. Ethical Criticism: Theory of Symbols (15 ${ }^{\text {th }}$ ed.). Princeton University Press, Princeton and Oxford.

[8] Fouzia, D. (2014). Interpretation of the Symbol Black Cat in Edgar Allan Poe's Short Story. p. 5. Retrived June, 2016, from https://bu.univ-ouargla.dz/master/pdf/Djaafour-Fouzia.pdf?idmemoire=4315.

[9] Hornby, A. S. (2005). S. Wehmeier, et al. (Ed.), Oxford Advanced Learner's Dictionary of Current English (7 ${ }^{\text {th }}$ ed., p. 1556). Oxford University Press, Oxford.

[10] McDonald, T. (20015). Seeing Poe's Fight with Alcoholism through his stories 'The Black Cat' and 'The Cask of Amontillado'. Retrived Febrarury 22, 2017, from http://trentsworld.com/postings/research-paper-poe.pdf.

[11] Poe, E. A. (1899). J. H. Ingram (Ed.), The Works of Edgar Allan Poe (standard ed., vol. 1). A. and C. Black.

[12] Poe, E. A. The Works of Edgar Allan Poe (Raven ed., vol. 1). Project Gutenberg, 1 - 5. Retrived Febrarury , 2016, from http://manybooks.net/titles/poeedgaretext00poe1v10.html.

[13] Potter, P. (June 2003). About the Cover. Emerging Infectious Diseases (vol. 9, no. 6), p. 760. Retrived August 2015 from http://wwwnc.cdc.gov/eid/pdfs/vol9no6_pdf-version.pdf.

[14] Rahman, S. (2015). Significance of Symbolism in Edgar Allan Poe's Selected Works. Retrived Febrarury, 2016, from http://dspace.bracu.ac.bd:8080/xmlui/bitstream/handle/10361/4984/Shegufta\%20Rahman.pdf?sequence=1 .

Hatameh Sadat Jandaghi is currently an M.A student of English Literature in Vali - e - Asr University. She got her B.A in English Translation from Vali - e - Asr University.

Esmaeil Zohdi received his BA from Chandigarh India1984 and in 1986 his M.A and his PhD from Calcutta University in 2000. He has been a member of the VRU(Vali-e-Asr University of Rafsanjan) since 2000, teaching English Literature.

Dr.Esmaeil Zohdi's publications, Two translations books and a Survey of Literature under publishing. He has published more than 40 articles in recognized Journals and presented more than 20 articles in national and international Conferences. He is a member of Psyart Foundation. 